\title{
Células-tronco mesenquimais aplicadas nas fases inflamatória e proliferativa da cicatrização de feridas cutâneas
}

\author{
[Mesenchymal stem cells applied to the inflammatory and proliferative phases of wound healing] \\ W.K. Beheregaray ${ }^{1}$, G.C. Gianotti ${ }^{2}$, F. Oliveira $^{3}$, P. Terraciano ${ }^{3}$, S. Bianchi ${ }^{2}$, S. Vidor ${ }^{2}$, \\ C.F. Marcolan ${ }^{1}$, E.A. Contesini ${ }^{2}$, E.O. Cirne-Lima ${ }^{3}$
}

${ }^{1}$ Centro Universitário Ritter dos Reis - UniRitter - Porto Alegre, RS

${ }^{2}$ Universidade Federal do Rio Grande do Sul - UFRGS - Porto Alegre, RS

${ }^{3}$ Hospital de Clínicas de Porto Alegre - Porto Alegre, RS

\begin{abstract}
RESUMO
A cicatrização de feridas é um processo que requer a interação de várias células da derme e epiderme. $\mathrm{O}$ objetivo deste trabalho foi avaliar qual o momento da aplicação das células das ADSCs em feridas cutâneas agudas que faria diferença na cicatrização nos primeiros sete dias da lesão. As células-tronco foram isoladas do tecido adiposo de camundongos C57B1/6 $\mathrm{GFP}^{+}$. Para tanto, foram utilizados 49 camundongos $\mathrm{C} 57 \mathrm{Bl} / 6$, divididos em quatro grupos: grupo I (GI/controle; $n=14)$; grupo II $(\mathrm{GII} ; \mathrm{n}=14)$ : ADSCs injetadas no d0; grupo III (GIII; $n=14$ ): ADSCs injetadas no terceiro dia; e Grupo IV (GIV; $n=7$ ): ADSCs injetadas no quinto dia. As avaliações clínicas ocorreram nos dias zero, três, cinco e sete, e as histopatológicas nos dias cinco e sete. Na metodologia proposta, foi observado que o uso de ADSCs aumenta a vascularização, a formação de tecido de granulação, a colagenização e incrementa o número de folículos pilosos em apenas sete dias de avaliação. Além disso, o momento da aplicação das células não repercutiu diferenças significativas nas fases inflamatória e proliferativa do processo de cicatrização das feridas cutâneas.
\end{abstract}

Palavras-chave: cicatrização cutânea, fase inflamatória, fase proliferativa, células-tronco mesenquimais derivadas de tecido adiposo

\begin{abstract}
Wound healing is a process that requires the interaction of various cells in the dermis and epidermis. The aim of this study was to evaluate the action of ADSCs in the treatment of acute wounds in order to understand if application time of the cells results in a difference in healing the first seven days of injury. The stem cells were isolated from adipose tissue of C57BL / 6 mice GFP +. Thus, we used 49 mice C57BL / 6 divided into four groups: Group I (GI / control, $n=14)$; Group II (GII; $n=14)$ : ADSCs injected to the d0; Group III (GIII; $n=14)$ : ADSCs injected on the 3rd day, and Group IV (GIV; $n=7)$ : ADSCs injected day 5(d5). Clinical evaluations were performed on days 0, 3, 5 and 7 and the histopathology on days 5 and 7. In the proposed methodology, the use of ADSCs increased vascularization, formation of granulation tissue, collagen deposition and increases the number of hair follicles in just seven days of evaluation. In addition, the time of application of the cells did not affect significant differences in the inflammatory and the proliferative phase of wound healing skin.
\end{abstract}

Keywords: cutaneous wound healing, inflammatory phase, proliferative phase, adipose mesenchymal stem cell

\section{INTRODUÇÃO}

A cicatrização de feridas é um evento complexo e multifatorial, que envolve interação do processo de inflamação, formação de tecido de

Recebido em 28 de setembro de 2016

Aceito em 3 de dezembro de 2016

E-mail: wbeherega@gmail.com granulação, reepitelização e angiogênese. O tratamento de ferida aguda, ou seja, aquele que é realizado tão logo aconteça a lesão, previne a sua cronificação e, consequentemente, a morbidade, bem como reduz os custos envolvidos (Balbino et al., 2005). 
O uso de MSCs em feridas agudas ou crônicas resulta em uma aceleração no processo cicatricial, em decorrência do impacto positivo que elas trazem para todas as fases da cicatrização (inflamatória, proliferativa e remodelamento) (Hocking, 2012; Maxson et al., 2012). Dessa forma, observa-se um aumento na migração epitelial, na angiogênese e na taxa de cicatrização, além da conformação de uma cicatriz menos evidente (Hassan et al., 2014; Jackson et al., 2012). Quando as MSCs são aplicadas diretamente na lesão ou na sua periferia, elas ali se enxertam e se diferenciam em vários tipos de células cutâneas (ceratinócitos, células endoteliais e pericitos), o que incrementa o processo de cicatrização (Brower et al., 2011). A neovascularização e a reepitelização são as principais razões para o efeito cicatricial dessa terapia (Jackson et al., 2001). A angiogênese é um processo que ocorre na fase proliferativa da cicatrização de feridas e será ela que proverá a nutrição necessária para os fibroblastos, que irão produzir o tecido de granulação (King et al., 2014). As MSCs facilitam a revascularização pela ação parácrina secretando FGF e VEGF-A, os quais promovem a proliferação, migração e diferenciação das células endoteliais dos vasos. Além disso, as MSCs facilitam a revascularização por meio da diferenciação em pericitos (células do endotélio vascular) (Maxson et al., 2012).

As vias usuais de aplicação de MSCs na cicatrização de feridas são a intravenosa e a local, sendo esta a mais indicada (McFarlin et al., 2006; Wu et al., 2007b; Sasaki et al., 2008). Os métodos de aplicação local de células incluem: injeção ao redor da ferida, spray tópico de fibrina e a incorporação a um scaffold (Hanson et al., 2010). O período em que é administrada também deve ser considerado, pois as MSCs devem interagir com células essenciais nos diferentes estágios do processo de cicatrização. Exatamente o que são essas interações e quando elas ocorrem constituem, atualmente, áreas de pesquisas a serem exploradas (Sorrell e Caplan, 2010).

O objetivo deste trabalho foi avaliar qual o momento da aplicação das células das ADSCs em feridas cutâneas agudas que faria diferença na cicatrização nos primeiros sete dias da lesão.

\section{MATERIAL E MÉTODOS}

Para a elaboração deste projeto, foram utilizados camundongos (Mus musculus) C57B1/6 $(\mathrm{n}=49)$ e camundongos $\mathrm{C} 57 \mathrm{Bl} / 6 \mathrm{GFP}^{+}(\mathrm{n}=34)$ com oito semanas de idade, hígidos e peso variando de 20$25 \mathrm{~g}$. Os camundongos provieram de biotérios de criação e foram alojados em gaiolas, onde receberam como alimento ração comercial e água ad libitum. Os procedimentos de finalização seguiram as normas indicadas pelas Diretrizes da Prática de Eutanásia do CONCEA (2013). O projeto foi avaliado pelo Comitê de Ética em Pesquisa em Animais do Hospital de Clínicas de Porto Alegre e aprovado sob o número de registro 130509.

Os animais foram divididos em quatro grupos, de forma aleatória, sendo distribuídos da seguinte maneira: grupo I (GI/controle; $\mathrm{n}=14)$ : os animais receberam $40 \mu \mathrm{L}$ de solução de $\mathrm{NaCl} 0,9 \%$ injetados ao redor da ferida após a indução das lesões (d0); grupo II (GII; $\mathrm{n}=14)$ : os animais receberam ADSC injetadas ao redor das feridas no d0; grupo III (GIII; $\mathrm{n}=14$ ): os animais receberam ADSC injetadas ao redor das feridas no terceiro dia após a indução da lesão (d3); e grupo IV (GIV; $\mathrm{n}=7)$ : os animais receberam ADSC injetadas ao redor das feridas no quinto dia após a indução da lesão (d5).

O isolamento de células-tronco mesenquimais derivadas de tecido adiposo foi realizado a partir da gordura inguinal de camundongos C57B1/6 $\mathrm{GFP}+$. O tecido adiposo coletado foi degradado por via enzimática em solução de colagenase $(1 \mathrm{mg} / \mathrm{mL})$ e incubado em banho-maria por 40 minutos, com agitação a cada 10 minutos. A suspensão celular obtida foi centrifugada, posteriormente plaqueada em placas de seis poços com meio de cultivo Dulbecco's Modified Eagle Medium (DMEM) (Gibco) suplementado com $1 \%$ de antibiótico e $20 \%$ de soro fetal bovino e, depois, foi mantida em estufa a $37^{\circ} \mathrm{C}$ e $5 \%$ de $\mathrm{CO}_{2}$. Após 24 horas do isolamento, aspirou-se todo o meio (juntamente com as células não aderentes) e foram adicionados 2,5mL de meio fresco em cada poço. Quando atingiram a quarta passagem, as células foram caracterizadas em adipócitos, condrócitos e osteócitos. As imagens da diferenciação podem ser observadas na Fig. 1. 


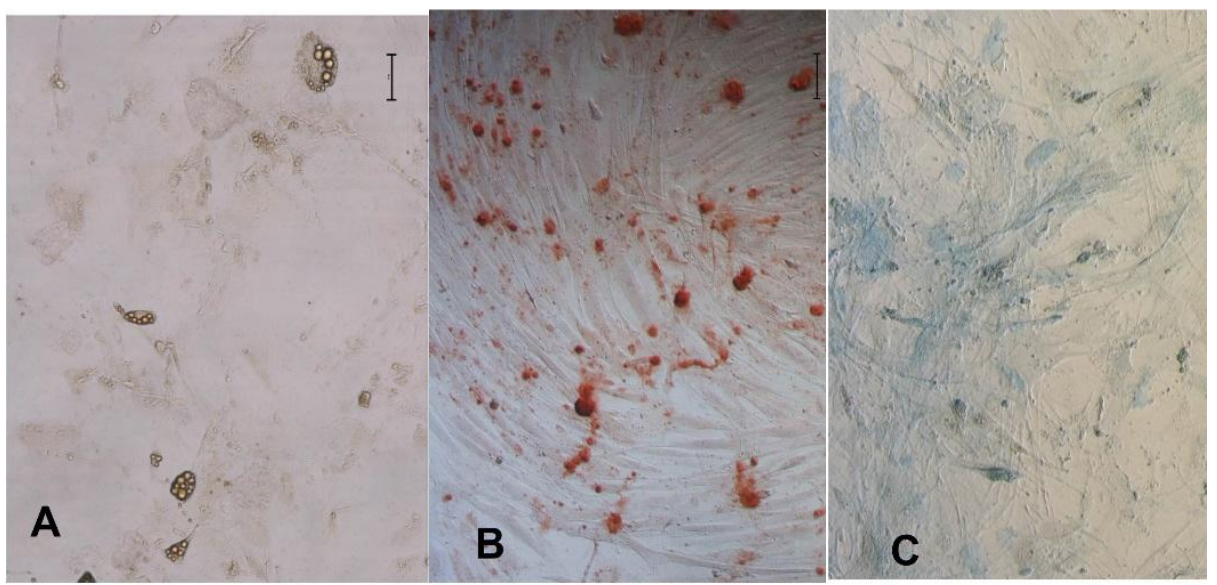

Figura 1. Ensaio de diferenciação das células-tronco mesenquimais derivadas de tecido adiposo (ADSCs), oriundas da coleta de tecido adiposo de camundongos C57B1/6 GFP positivo. Cultivadas em meio apropriado, as ADSCs se diferenciaram em adipócitos (A), indicado pelo acúmulo de vacúolos de lipídios nas células; osteoblastos (B), indicado em vermelho pelos depósitos de cálcio presentes na matriz extracelular dos osteócitos; condrócitos (C), indicado pela cor azul dos glicosaminoglicanos sulfatados secretados pela matriz extracelular dos condroblastos.

Os animais foram submetidos à anestesia geral, utilizando-se isolurano $2,5 \%$ vaporizado em $0,5 \mathrm{~L}$ de oxigênio $100 \%$, por meio de máscara. Com os animais sedados, foi realizada tricotomia ampla na região do dorso e a aplicação de tramadol $10 \mathrm{mg} . \mathrm{kg}^{-1}$, por via intraperitoneal. Com um molde circular de $6 \mathrm{~mm}$ de diâmetro, foi delimitada a área da lesão cutânea a ser induzida: na região do dorso entre as duas escápulas. Os animais que pertenciam aos grupos tratados com células-tronco receberam ADSCs injetadas ao redor das feridas, por via subcutânea, em quatro pontos de igual distância entre si (tomando-se como base a localização no relógio: 12 horas, 15 horas, 18 horas e 21 horas), na concentração de $1 \times 10^{6}$, diluídas em $40 \mu \mathrm{L}$ de solução estéril de $\mathrm{NaCl} 0,9 \%$. No grupo controle, a solução de $\mathrm{NaCl} 0,9 \%$ foi injetada ao redor das feridas, por via subcutânea, nos quatro pontos. As feridas induzidas foram cobertas pelo curativo transparente e adesivo (Opsite, Smith \& Nephew).

As avaliações macroscópicas ocorreram nos dias (d) $0,3,5$ e 7. Para as avaliações d3, d5 e d7, os animais foram sedados conforme descrito anteriormente. As feridas foram mensuradas em duas direções, o maior comprimento pela menor largura, com auxílio de paquímetro digital. A área de contração da ferida (C) foi calculada subtraindo-se a área inicial (a1), determinada no dia da primeira aferição da lesão, da área da lesão (a) nos dias de mensuração. Assim, $\mathrm{C}=\mathrm{a} 1$ a. Também foi avaliada a taxa de contração cicatricial (Tc) com base nesses resultados $(\mathrm{Tc}=\mathrm{C} \times 100 / \mathrm{a} 1)$. Ainda, foram feitos registros fotográficos durante as mensurações, e os aspectos macroscópicos, como presença de tecido necrótico, granulação, sinais de infecção, presença de exsudato, hiperemia, hiperpigmentação, edema, cianose e crosta, quando observados, foram anotados em fichas controle.

Para avaliação histológica, os animais foram, primeiramente, submetidos à eutanásia pelo método de sobredose anestésica seguida de deslocamento cervical, para, só então, proceder à remoção da área da ferida com uma margem de $2 \mathrm{~mm}$ de pele saudável. As amostras coletadas para avaliação histológica foram imediatamente acondicionadas em formol tamponado a $10 \%$. Os segmentos foram processados pela técnica rotineira de inclusão em parafina. Os animais foram avaliados no $\mathrm{d} 5$ ( $\mathrm{n}=7$ por grupo) ou $\mathrm{d} 7$ $(\mathrm{n}=7$ por grupo).

Para a avaliação do processo cicatricial e da qualidade cicatricial, os cortes histológicos foram corados pela técnica de hematoxilina e eosina (HE), e pelo tricômico de Masson (TM), para se analisar a presença de fibras colágenas existentes nos locais de fibrose do interstício. $\mathrm{Na}$ avaliação das características microscópicas da 
cicatrização, foram consideradas: proliferação vascular e fibroblástica; presença de células mononucleares e polimorfonucleares; colagenização; reepitelização; presença de folículos pilosos; e a queratinização (Tab. 1).
Na Tab. 1, estão dispostos os índices histológicos utilizados neste experimento. Foram realizados testes imuno-histoquímicos, com o objetivo de avaliar o perfil proliferativo (anti-Ki 67), enxertia das ADSCs (anti-GFP) e a angiogênese (anti-cd31) durante o processo cicatricial.

Tabela 1. Índice histológico utilizado como critério para avaliação da cicatrização de feridas cutâneas induzidas experimentalmente em camundongos $\mathrm{C} 57 \mathrm{Bl} / 6$, que foram tratados, conforme o grupo pertencente, com células-tronco mesenquimais adiposo derivadas, oriundas de camundongos C57B1/6 GFP positivo. Os valores variam entre 0 e 3, com base nos índices de proliferação vascular, células mononucleares, células polimorfonucleares, proliferação fibroblástica, colagenização, reepitelização, folículos pilosos, queratina, proliferação celular, GFP positivo e anti-CD31

\begin{tabular}{|c|c|c|c|c|}
\hline & \multicolumn{4}{|c|}{ Índice histológico } \\
\hline & 0 & 1 & 2 & 3 \\
\hline Proliferação vascular & 0 & $1-5$ & $5-15$ & $>15$ \\
\hline Células mononucleares & 0 & $<50$ & $50-100$ & $>100$ \\
\hline Células polimorfonucleares & 0 & $<50$ & $50-100$ & $>100$ \\
\hline Proliferação fibroblástica & 0 & $<50$ & $50-100$ & $>100$ \\
\hline Colagenização $^{a}$ & 0 & $<10$ & $10-30$ & $>30$ \\
\hline Reepitelização ${ }^{\mathrm{b}}$ & 0 & $<1$ & $1-2$ & $>2$ \\
\hline Folículos pilosos ${ }^{c}$ & 0 & $<30 \%$ & $30-60 \%$ & $>60 \%$ \\
\hline Queratina $^{\mathrm{d}}$ & 0 & $1 x$ & $2-3 x$ & $>3 x$ \\
\hline Proliferação celular & 0 & $<20$ & $20-100$ & $>100$ \\
\hline GFP positivo $^{\mathrm{e}}$ & 0 & $<20$ & $20-100$ & $>100$ \\
\hline Anti-CD31 & 0 & $1-5$ & $5-15$ & $>15$ \\
\hline
\end{tabular}

${ }^{a}$ Avaliação feita na região sublesional; ${ }^{b}$ relação feita por meio da visualização de um campo de $400 x$; ${ }^{c}$ porcentagem estabelecida em relação ao tamanho do bulbo do folículo piloso; ${ }^{d}$ proporção feita em relação ao tamanho da lâmina basal do epitélio; ${ }^{\mathrm{p}}$ positivo, foi avaliado pela intensidade da marcação e da área marcada

A análise estatística utilizou o modelo de equações de estimativas generalizadas para as medidas ao longo do tempo e a correção de Bonferroni para as comparações múltiplas. $\mathrm{Na}$ comparação de variáveis quantitativas no tempo basal, foi utilizada a análise de variância, seguida do teste de Tukey. As variáveis categóricas foram descritas por frequências e percentuais e associadas pelo teste exato de Fisher. Foram correlacionadas as variáveis quantitativas entre si pelo coeficiente de correlação de Pearson. O nível de significância utilizado para rejeitar a hipótese de nulidade foi de $5 \%(\mathrm{P}<0,05)$.

\section{RESULTADOS}

Nas avaliações clínicas no pós-operatório imediato, não foram observadas diferenças estatisticamente significativas na área inicial da ferida induzida (média $=6,1 \mathrm{~mm}$ ) entre os grupos $(\mathrm{P}=0,71)$. Durante o exame das feridas, não foram encontrados sinais de necrose, cianose e hiperpigmentação na área das lesões. Além disso, não foram observados sinais de dor em nenhum dos animais experimentados.

A presença do tecido de granulação foi avaliada atribuindo-se valores de zero a três, conforme a sua localização na lesão, de acordo com o seguinte: valor zero para ausência de tecido de granulação; valor um para tecido localizado nas margens; valor dois para tecido localizado na região central; e valor três para o caso de a granulação cobrir toda a lesão. Todos os animais, independentemente do grupo, evoluíram de zero para três. Verificou-se a diferença estatística significativa do grupo GIV (28,6\% presente, $\mathrm{P}=0,05)$ no segundo dia de avaliação, sendo que, nesse mesmo grupo, o tecido de granulação se localizava nas margens da lesão em $33 \%$ $(\mathrm{P}=0,043)$. Nos outros momentos de avaliações, não há diferença significativa entre os grupos para esse critério. As crostas sobre as lesões foram observadas em $15,8 \%$ das avaliações realizadas no período de experimentação. Essa porcentagem foi distribuída da seguinte maneira 
entre os grupos: $36,5 \%$ no GI; $12,1 \%$ no GII; $26,8 \%$ no GIII; e $24,3 \%$ no GIV, não havendo diferença significativa entre os grupos.

Foi observada hiperemia na ferida ou circunjacente a ela em apenas quatro momentos de avaliação, sendo todos de animais diferentes e pertencentes ao GI. Com relação à categoria edema, foi observado que $33,3 \%$ do GI tinham edema na segunda avaliação $(\mathrm{P}=0,026)$ e $20 \%$ na terceira avaliação $(\mathrm{P}=0,06)$. Além disso, constatou-se que todos os animais que apresentavam hiperemia também apresentavam edema.

Em 8,8\% das avaliações, foi observada a presença de exsudato nas lesões, sendo $43 \%$ no GI, $17,3 \%$ no GII e GIII e $21 \%$ no GIV. Em relação à característica do exsudato, observou-se $21,7 \%$ de purulentos, $39,1 \%$ de serosos e $39,1 \%$ de serosanguinolentos. Não foi observada diferença significativa entre os grupos.

$\mathrm{Na}$ avaliação da velocidade cicatricial dentro de cada grupo, pôde-se observar diferença estatística entre cada avaliação, exceto da segunda para a terceira no GIV e entre a terceira e a quarta avaliação dos GI e GII. Pôde-se observar diferença significativa na taxa de cicatrização somente na segunda avaliação entre os grupos GI $(5,4 \%)$ e GIV $(30,47 \%)$, com $\mathrm{P}=0,034$. $\mathrm{O}$ comportamento da taxa de cicatrização nos diferentes grupos pode ser observado na Fig. 2, e as imagens representativas das lesões no terceiro, quinto e sétimo dias nos diferentes grupos podem ser analisadas na Fig. 3.

Para a análise histológica, as variáveis empregadas, segundo os critérios descritos na Tab. 1, foram: proliferação vascular, células mononucleares, células polimorfonucleares, proliferação fibroblástica, colagenização, reepitelização, folículos pilosos, ceratina, proliferação celular, GFP positivo e anti-CD31.

As imagens histológicas podem ser visualizadas na Fig. 4. O GIII apresentou diferença significativa quando comparado ao GI nas variáveis proliferação vascular $(\mathrm{P}=0,019) \mathrm{e}$ colagenização $(\mathrm{P}=0,015)$. Para a presença de folículos pilosos, o GII apresentou diferença significativa $(\mathrm{P}=0,05)$ em relação ao $\mathrm{GI}$.

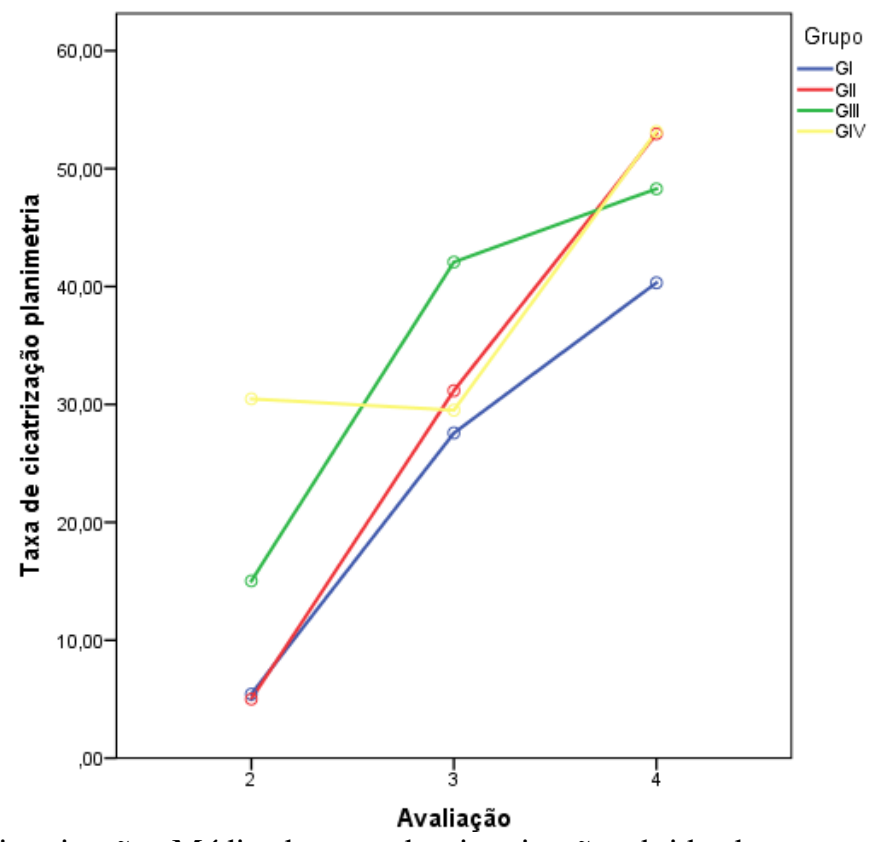

Figura 2. Taxa de cicatrização. Média da taxa de cicatrização obtida durante as avaliações de lesões cutâneas induzidas em camundongos $\mathrm{C} 57 \mathrm{Bl} / 6$ tratados com células-tronco mesenquimais derivadas de tecido adiposo (ADSCs) isoladas de camundongos B C57B1/6 6 GFP positivo conforme o grupo pertencente: GI (grupo controle); GII (ADSCs injetadas no dia zero); GIII (ADSCs injetadas no dia três); GIV (ADSCs injetadas no dia cinco) e verificadas em quatro momentos diferentes do pós-operatório: imediato (avaliação 1); terceiro dia; (avaliação 2); quinto dia (avaliação 3); e sétimo dia (avaliação 4). 
G
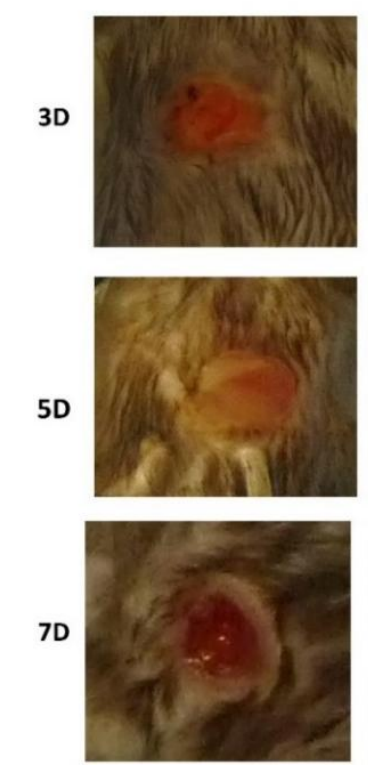

GII
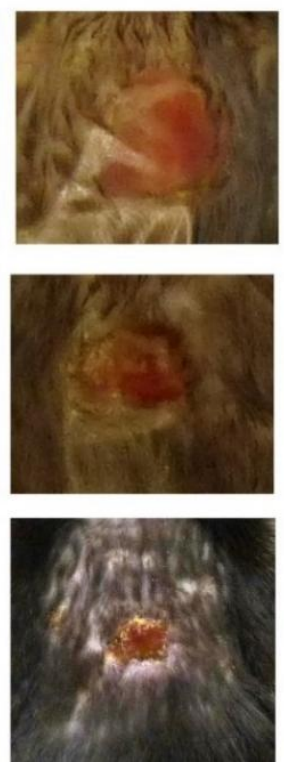

GIII
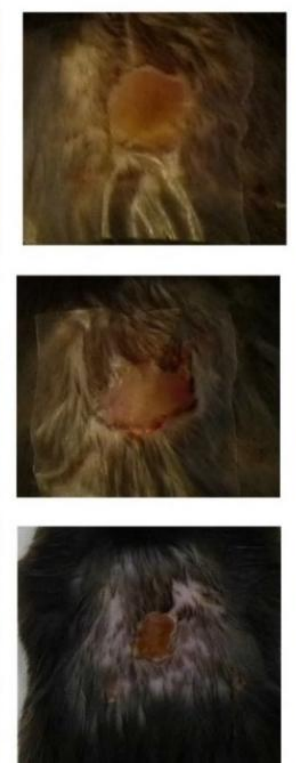

GIV
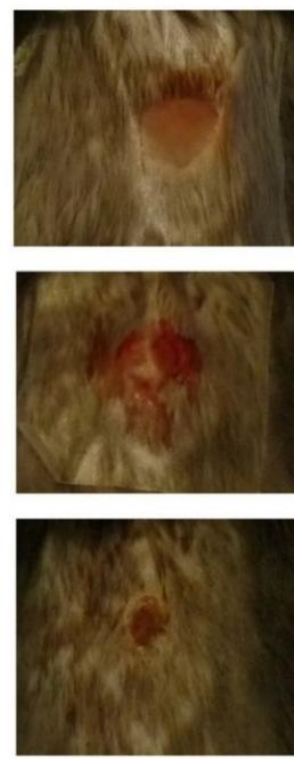

Figura 3. Aspecto das feridas durante as avaliações nos dias três, cinco e sete de pós-operatório de lesões cutâneas induzidas em camundongos C57B1/6 tratados com células-tronco mesenquimais derivadas de tecido adiposo (ADSCs) isoladas de camundongos C57B1/6 GFP positivo conforme o grupo pertencente: GI (grupo controle); GII (ADSCs injetadas no dia zero); GIII (ADSCs injetadas no dia três); e GIV (ADSCs injetadas no dia cinco). Apesar da pequena diferença na velocidade cicatricial, as feridas tratadas com ADSCs apresentavam uma cicatrização mais cosmética do que as do grupo controle.
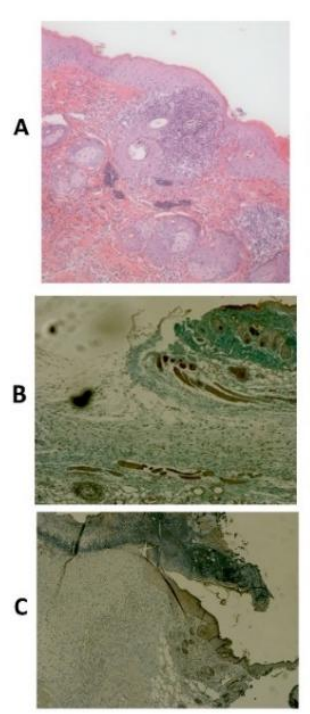

GII
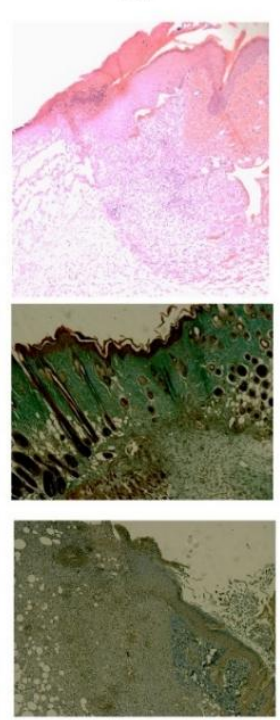

GIII
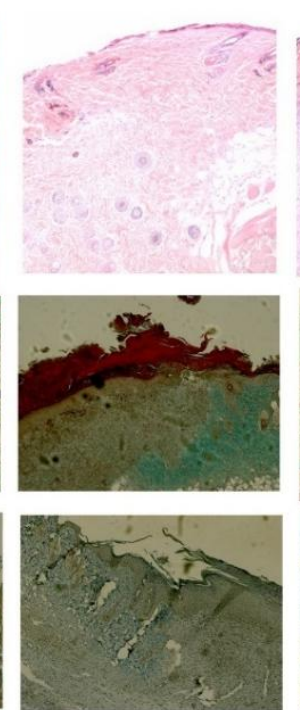

GIV
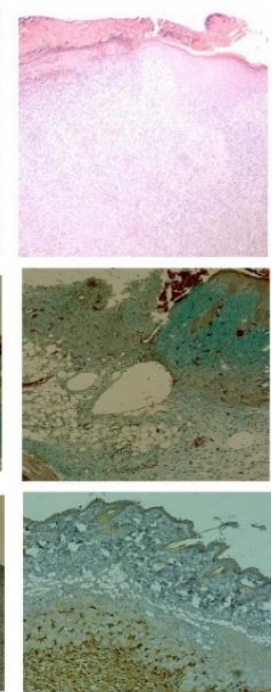

Figura 4. Avaliação histológica de ferida cutânea em camundongos C57Bl/6 tratados com células-tronco mesenquimais derivadas de tecido adiposo (ADSCs) isoladas de camundongos C57Bl/6 GFP positivo, em aumento de 400x. (A) Coloração de hematoxilina e eosina para avaliação da qualidade cicatricial. (B) Coloração de tricrômio de Masson para a presença de fibras colágenas. (C) Anti-GFP marca a enxertia das ADSCs. GI (grupo controle); GII (ADSCs injetadas no dia zero); GIII (ADSCs injetadas no dia três); e GIV (ADSCs injetadas no dia cinco). 
O GIV se destaca pela presença de anti-CD31 (57,1\% apresentam índice 3 ) em relação ao GI (71,4\% apresentam índice 1),valores estes que não configuram diferença estatística significativa; entretanto, há a análise de resíduo ajustado, que mostra um valor $>1,96(2,3)$.

$\mathrm{Na}$ avaliação da presença de ADSCs enxertadas na ferida (anti-GFP), pôde-se verificar diferença significativa do GI $(0 \%)$ em relação aos demais grupos $(\mathrm{P}=0,00)$. Já o GIII apresentou $71,4 \%$ no índice 2 e o GIV, 57,1\%; o GIV e o GII apresentaram uma distribuição uniforme entre os

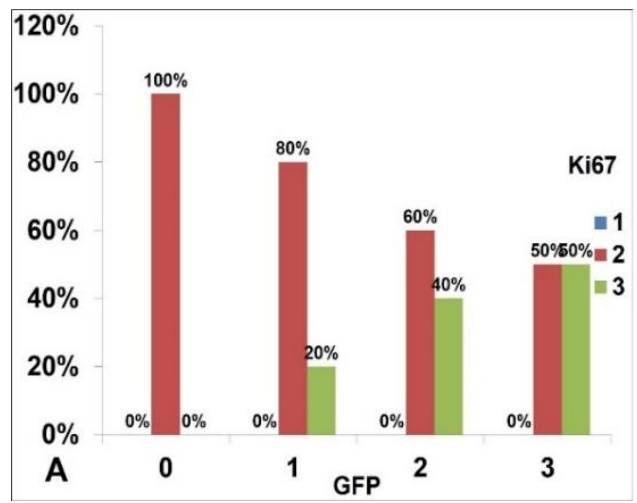

índices 1,2 e 3 . Na avaliação realizada cinco dias após a indução da lesão, pôde-se observar uma relação diretamente proporcional entre antiGFP e Ki67 (P = 0,027), ou seja, quanto maior o número de ADSCs enxertadas, maior é o índice de Ki67. Esse mesmo comportamento foi observado ao se relacionar anti-GFP e CD31 $(\mathrm{P}=0,00)$. Contudo, na avaliação de sete dias, a relação entre anti-GFP e Ki67 não apresentou diferença significativa; apesar disso, a relação observada entre anti-GFP e CD31 manteve a mesma diferença $(\mathrm{P}=0,00)$ (Fig. 5 e 6$)$.

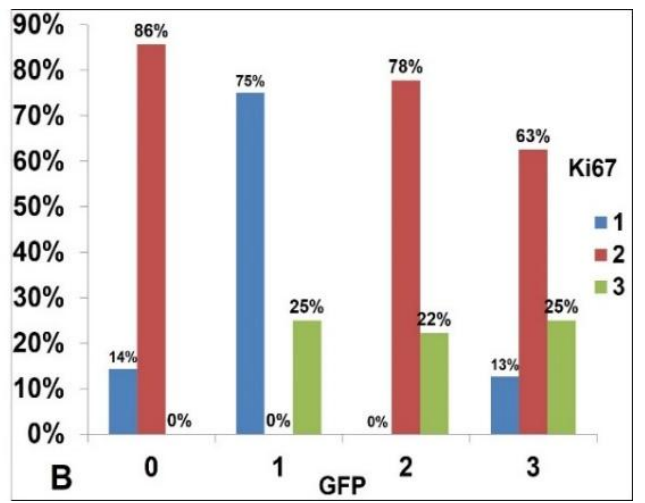

Figura 5. Relação entre a enxertia de ADSCs (GFP+) e o marcador de proliferação celular KI67 aos cinco dias (A) e aos sete dias (B). As lesões cutâneas foram induzidas em camundongos C57B1/6 tratados com células-tronco mesenquimais derivadas de tecido adiposo (ADSCs) isoladas de camundongos C57B1/6 GFP positivo conforme o grupo pertencente. A análise foi feita utilizando-se critério de $0=$ ausente, $1=\leq$ $20 \%, 2 \leq 20-100 \%$ e $3=>100 \%$ para GFP positivo e KI67 nos grupos GI (grupo controle); GII (ADSCs injetadas no d0); GIII (ADSCs injetadas no d3); e GIV (ADSCs injetadas no d5). Observou-se uma relação diretamente proporcional entre anti-GFP e Ki67 (P=0,027) no 5d.
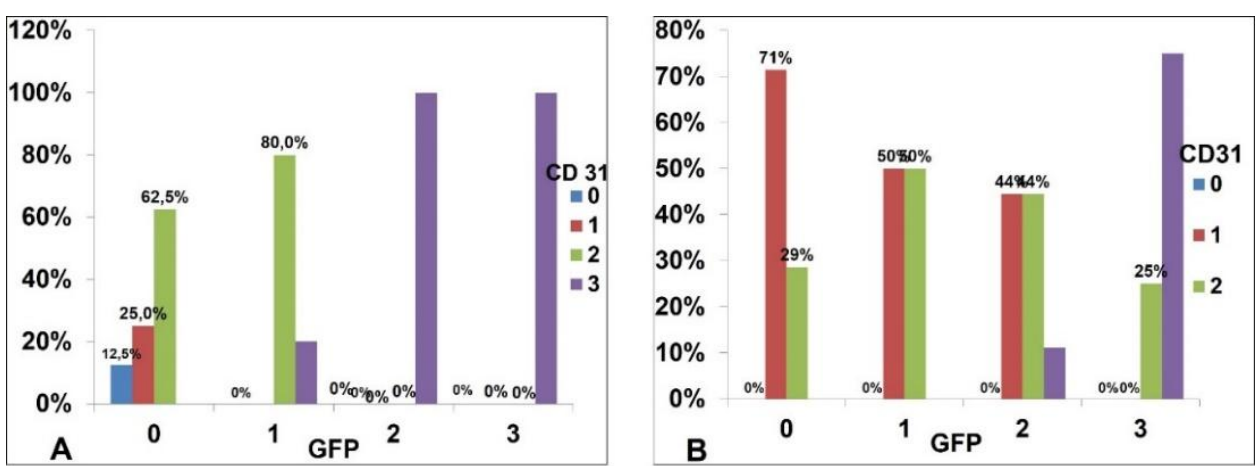

Figura 6. Relação entre a enxertia de ADSCs (GFP+) e o marcador de proliferação vascular CD31 aos cinco dias (A) e aos sete dias (B). As lesões cutâneas foram induzidas em camundongos C57Bl/6 tratados com células-tronco mesenquimais derivadas de tecido adiposo (ADSCs) isoladas de camundongos C57Bl/6 GFP positivo conforme o grupo pertencente. A análise foi feita utilizando-se critério de $0=$ ausente, $1=\leq 20 \%, 2=\leq 20-100 \%$ e $3=>100 \%$ para GFP positivo e de $0=$ ausente, $1=1-5,2=5-15 \%$ e $3=>15$ de CD31. Os grupos foram distribuídos em GI (grupo controle); GII (ADSCs injetadas no d0); GIII (ADSCs injetadas no d3); e GIV (ADSCs injetadas no d5). Relação diretamente proporcional entre anti-GFP e CD31 $(\mathrm{P}=0,00)$ aos $5 \mathrm{~d}$ e $7 \mathrm{~d}$. 


\section{DISCUSSÃO}

Com base no presente estudo, foi observado que o uso de ADSCs aumenta a vascularização, a formação de tecido de granulação, a colagenização e incrementa o número de folículos pilosos em apenas sete dias de avaliação.

Os trabalhos publicados na área de reparo cutâneo não costumam fornecer dados clínicos sobre a avaliação da cicatrização, restringindo-se normalmente à avaliação da área cicatricial por medições ou registros fotográficos e pelas características microscópicas (Wu et al., 2007b; Chen et al., 2009; Nambu et al., 2009; Lim e Yoo, 2010; Nie et al., 2011; Noguchi et al., 2014). Parâmetros clínicos avaliados neste experimento, entre os quais a presença de exsudato, edema, hiperemia e tecido de granulação, apresentaram diferença significativa entre os grupos experimentados. Ainda, exsudato, edema e hiperemia são características que demonstram a inflamação da ferida, e pôdese constatar que o GI apresentava maiores médias, com significância, nesses critérios que os grupos tratados com ADSCs. Além disso, todos os animais que tinham hiperemia também apresentavam edema, o que comprova a instauração de um processo inflamatório. Por meio dessa observação, pôde-se constatar a ação anti-inflamatória promovida pelas MSCs já largamente descrita na literatura (Amorin et al., 2012; Maxson et al., 2012; Hassan et al., 2014), porém somente baseada em aspectos histológicos e não clínicos, como nesse caso apresentado. Com isso, pode-se indicar a avaliação clínica das lesões como uma ferramenta importante no processo de investigação da cicatrização cutânea.

Wu et al. (2007a) demonstraram que as feridas tratadas com BMSC promovem a angiogênese e apresentam maior densidade capilar. No presente estudo, as feridas tratadas com ADSCs tiveram aumento da proliferação vascular quando comparadas com o grupo não tratado; em especial o GIII apresentou 71,4\% de proliferação vascular em índice 3, enquanto o GI apresentou $0 \%(\mathrm{P}=0,019)$ na avaliação histológica $5 \mathrm{~d}$. A angiogênese é um processo que ocorre na fase proliferativa da cicatrização de feridas e é ela que suprirá a nutrição necessária para os fibroblastos que irão produzir o tecido de granulação (King et al., 2014). As MSCs facilitam a revascularização pela ação parácrina, secretando FGF e VEGF-A, os quais promovem a proliferação, migração e diferenciação das células endoteliais dos vasos. Além disso, as MSCs facilitam a revascularização por meio da diferenciação em pericitos (células da parede vascular) (Maxson et al., 2012).

Durante a fase proliferativa da cicatrização, observou-se que a síntese de colágeno aumenta na região da lesão, enquanto a proliferação de fibroblastos diminui sucessivamente, ajustando-se um equilíbrio entre a síntese e a degradação da matriz extracelular (Reinke e Sorg, 2012). Dessa forma, pôde-se observar que o GIII apresentava índice 3 de colagenização enquanto o GI apresentava $0 \%$ nesse índice na avaliação histológica do $5 \mathrm{~d}(\mathrm{P}=$ 0,015). Ainda, observou-se que a proliferação fibroblástica apresentava 75\% em índice 3 no GI, comprovando a informação que mostra a proporção inversa desses dois critérios.

Estudos têm demonstrado que a administração de MSCs em lesões agudas de roedores melhora a taxa de cicatrização por acelerar a epitelização, o que aumenta a formação de tecido de granulação e a angiogênese (Maxson et al., 2012). Com base nisso, fez-se a relação entre a presença de ADSCs (GFP+) com o marcador de proliferação (anti-KI67) e constatou-se uma relação de proporcionalidade entre essas duas variáveis. Desse modo, foi verificado que quanto mais ADSCs (GFP+) o animal apresentava, maior era o índice de proliferação celular $(\mathrm{P}=0,027)$ no 5d. Da mesma forma, relacionou-se a presença de GFP+ com o marcador de angiogênese (antiCD31) e foi observada uma relação ainda mais forte, $\mathrm{P}=0,00$ no $5 \mathrm{~d}$ e no $7 \mathrm{~d}$. Esses achados confirmam a atuação das ADSCs no processo de cicatrização cutânea relatados na literatura atual (Hassan et al., 2014).

Ao serem comparados os momentos de aplicação das células, observou-se que não há diferenças significativas entre a aplicação imediatamente após a indução da lesão, no terceiro ou no quinto dia após a lesão, ao se avaliar o processo de cicatrização nos sete primeiros dias. Pode-se indicar, por meio dos resultados obtidos neste experimento, que a aplicação de ADSCs no 3d após lesão promove a proliferação vascular e a colagenização. Ainda, que o tratamento imediatamente após a lesão aumenta a presença 
de folículos pilosos e que a aplicação no $5 \mathrm{~d}$ aumenta a presença de tecido de granulação nos sete primeiros dias de cicatrização. Além disso, as maiores diferenças dos grupos tratados em relação ao controle foram observadas no quinto dia da lesão, e não no sétimo dia.

\section{CONCLUSÃO}

Mediante a metodologia aplicada neste estudo, pôde-se observar que a terapia com ADSCs promoveu a cicatrização de feridas por meio da proliferação celular e da angiogênese. Além disso, o momento da aplicação das células nas lesões cutâneas não repercutiu diferenças significativas nas fases inflamatória e proliferativa do processo de cicatrização de feridas cutâneas.

\section{REFERÊNCIAS}

AMORIN, B.; VALIM, V.; LEMOS, N.M. et al. immunological properties and clinical applications. Rev. HCPA, v.32, p.71-81, 2012.

BALBINO, CA; PEREIRA, L.M; CURI, R. Mecanismos envolvidos na cicatrização: uma revisão. Rev. Bras. Cienc. Farm., v.41, p.27-51, 2005.

BROWER, J; BLUMBERG, S; CARROL, E. et al. Mesenchymal stem cell therapy and delivery systems in nonhealing wounds CM. Adv. Wound Care, v.24, p.524-532, 2011.

CHEN, M; PRZYBOROWSKI, M; BERTHIAUME, F. Stem cells for skin tissue engineering. Crit. Rev. Biomed. Eng., v.37, p.399-421, 2009.

Resolução Normativa CONCEA $\mathrm{n}^{\circ} 13$ de 20/09/2013. Diretrizes da Prática de Eutanásia do Conselho Nacional de Experimentação Animal CONCEA.

HANSON, S.; BENTZ, M.; HEMATTI, P. Mesenchymal stem cell therapy for nonhealing cutaneous wounds. Plast. Reconstr. Surg., v.125, p.510-516, 2010.

HASSAN, W.U; GREISER, U.; WANG, W. Role of adipose-derived stem cells in wound healing. Wound Repair Regen., v.22, p.313-25, 2014. Available in: <http://www.ncbi.nlm.nih.gov/pubmed/2484433 1>. Accessed in: 5 dez. 2014.
HOCKING, A.M. Mesenchymal stem cell therapy for cutaneous wounds. Adv. Wound Care, v.1, p.166-171, 2012.

JACKSON, D.; HAMBLY, C.; THAYHURN, P.; SPEAKMAN, J.R. Can non-shivering thermogenesis in brown adipose tissue following NA injection be quantified by changes in overlying surface temperatures using infrared thermography? J. Therm. Biol., v.26, p.85-93, 2001.

JACKSON, W.M.; NESTI, L.J.; TUAN, R.S. Mesenchymal stem cell therapy for attenuation of scar formation during wound healing. Stem Cell Res. Ther., v.20, p.1-9, 2012.

KING, A.; BALAJI, S.; KESWANI, S.G.; CROMBLEHOLME, T.M. The role of stem cells in wound angiogenesis. Adv Wound Care, v.3, p.614-625, 2014.

LIM, J.S.; YOO, G. Effects of adipose-derived stromal cells and of their extract on wound healing in a mouse model. J. Korean Med. Sci., v.25, p.746-751, 2010.

MAXSON, S.; LOPEZ, E.A.; YOO, D.; DANILKOVITCH-MIAGKOCA, A. Concise review: role of mesenchymal stem cells in wound repair. Stem Cells Transl. Med., v.1, p.142-149, 2012.

MCFARLIN, K.; GAO, X.; LIU, Y.B. et al. Bone marrow-derived mesenchymal stromal cells accelerate wound healing in the rat. Wound Repair Regen, v.14, p.471-478, 2006.

NAMBU, M.; KISHIMOTO, S.; NAKAMURA, S. et al. Accelerated wound healing in healingimpaired $\mathrm{db} / \mathrm{db}$ mice by autologous adipose tissue-derived stromal cells combined with atelocollagen matrix. Ann. Plas. Surg., v.62, p.317-321, 2009.

NIE, C.; YANG, D.; XU, J. et al. Locally administered adipose-derived stem cells accelerate wound healing through differentiation and vasculogenesis. Cell Transplantation, v.20, p.205-216, 2011.

NOGUCHI, F.; NAKAJIMA, T.; INUI, S. et al. Alteration of skin wound healing in keratinocytespecific mediator complex subunit 1 null mice. PloS one, v.9, p.e102271, 2014. Available in: <http://www.pubmedcentral.nih.gov/articlerende r.fcgi?artid=4133190\&tool=pmcentrez\&renderty pe=abstract $>$. Accessed in: 17 Nov. 2014. 
REINKE, J.M.; SORG, H. Wound repair and regeneration. Eur. Surg. Res,. v.49, p.35-43, 2012.

SASAKI, M.; ABE, R.; FUJITA, Y. et al. Mesenchymal stem cells are recruited into wounded skin and contribute to wound repair by transdifferentiation into multiple skin cell type. $J$. Immunol., v.180, p. 581-2587, 2008.

SORRELL, J.M.; CAPLAN, A.I. Topical delivery of mesenchymal stem cells and their function in wounds. Stem Cell Res. Ther., v.1, p.30, 2010.
WU, Y.; CHEN, L.; SCOTT, P.G.; TREDGET, E.E. Mesenchymal stem cells enhance wound healing through differentiation and angiogenesis. Stem Cells, v.25, p.2648-2659, 2007a.

WU, Y.; WANG, J.; SCOTT, P.G.; TREDGET;

E.E. Bone marrow-derived stem cells in wound healing: a review. Wound Repair Reg., v.15 Suppl.1, p.S18-26, 2007 b. 